Session 3275

\title{
Useful Approaches to Preventing Academic Dishonesty in the Classroom
}

\author{
Trevor S. Harding \\ Kettering University
}

\begin{abstract}
Over the past three decades, academic dishonesty (a.k.a. cheating) has become an increasingly common occurrence among college-aged students, and engineering students are known to be among the most frequent culprits. At most universities, cheating is dealt with after the fact. Few institutions go beyond drafting an academic integrity policy to prevent cheating before it happens. The same situation exists in the classroom. The majority of college professors report doing little or nothing to reduce the frequency of cheating in their classes, usually because of a lack of awareness of its occurrence. And when cheating is observed, faculty overwhelmingly choose to deal with the situation on their own, without resorting to the institution's policy. Given this scenario, it is the author's goal to develop useful approaches that help faculty prevent cheating before it occurs. In addition, the author feels that students do not inherently want to cheat. One can therefore assume that there is a set of practical techniques that can be used by faculty to reduce the pressure on students to cheat. This paper focuses on several of these techniques which were developed as a result of research on self-reported student cheating at a private mid-western university. One technique that is highly effective is the use of learning objectives for test construction. Students reported cheating less often on tests since they appeared to be written more fairly. Other techniques include discussing learning theories and engineering ethics in class, allowing students to use reference sheets for closed-book tests and having students work in cooperative learning groups on homework. Discussion will include how to apply these techniques and why they may reduce cheating.
\end{abstract}

\section{Introduction}

If one reviews the literature on academic dishonesty, they will find a rather alarming set of statistics. Maramark and Maline, based on 30 years of research on cheating in higher education, have recently declared that cheating is a "chronic" problem". A look at the numbers indicates why. The number of students who admitted to cheating in college has increased steadily, from $23 \%$ in the 1940 ' $^{2}$ to as many as $70 \%$ in the $1990 \mathrm{~s}^{3}$. For engineering educators, the numbers are even more disturbing. In a study conducted by Mead in 1992, the number of engineering students who admitted to cheating was around $74 \%$, second only to business students $(87 \%)^{4}$.

"Proceedings of the 2001 American Society for Engineering Education Annual Conference \& Exposition Copyright @ 2001, American Society for Engineering Education” 
Given this situation, one has to wonder what academic institutions have done to curtail the rising tide of student cheating and whether it has been effective. Nearly every 4-year institution and community college has an academic policy of some form for dealing with student cheating ${ }^{2}$. However, research indicates that these policies have a very mixed impact on student cheating. One reason for this is that many policies focus on defining cheating and the subsequent sanctions for cheaters, rather than on preventing cheating before it occurs and engendering a culture that encourages integrity among students.

There is, however, a further problem with academic dishonesty policies. Few faculty are familiar with their institution's policy, and even fewer actually report incidences of cheating to the appropriate people. In a survey of 800 faculty, only $6 \%$ reported that they often reported cases of cheating to the individual's responsible for their school's academic dishonesty cases, while 54\% said they seldomly reported cases and $40 \%$ never $\mathrm{did}^{5}$. In large part faculty prefer to deal with instances of cheating on their own rather than reporting cases to the administration. The reasons for this are varied, but frequently involve an institutional system that inhibits the reporting of cases, a lack of support from administration in difficult cases and the fear of litigation.

Given this scenario of increasing levels of cheating and a preference for faculty to deal with cheating within the classroom, the author felt that a discussion of practical methods to be used by faculty to prevent cheating prior to its occurrence was needed. This paper is based on preliminary results of a study being conducted by a team of researchers to investigate engineering students' perceptions about what is cheating, how often they do it and how it can be prevented. It is the author's personal belief that students do not inherently want to cheat for malicious reasons, but instead do so as a result of various demographic, situational and/or psychological factors. Therefore, a set of useable techniques should exist that can counteract these factors and help students avoid the temptation to cheat.

\section{Current Research on Cheating}

The primary assessment goals of the author's present research were to measure student perceptions of what constitutes cheating, the frequency of cheating and student attitudes about what actions might reduce cheating in a class. In particular, this last data set was used to develop teaching strategies to reduce the lure of cheating. Data were gathered from students in two different offerings of the Engineering Materials course (MFGE370). The course was offered during the Spring 2000 and Summer 2000 quarters.

Students were asked to complete a survey at the start of each term. Data was also taken at the end of the term to evaluate the effectiveness of techniques that were used in the Summer 2000 term; however, the available data set constituted a statistically small sample and is not included here. All student responses to the survey were anonymous.

A total of 65 students responded to the survey during the Spring and Summer 2000 quarters. Both classes were dominated by juniors (78\%) and had an average grade point of 87 (roughly 3.0 on a 4.0 scale). Of the total study population, $76 \%$ of respondents

"Proceedings of the 2001 American Society for Engineering Education Annual Conference \& Exposition Copyright @ 2001, American Society for Engineering Education” 
were male, $24 \%$ female. The ethnic distribution of the study group was $86 \%$ Caucasian, 6\% African American, 4.5\% Asian American and 3.5\% foreign student or "other". Both groups reported that similar numbers of family members had attended college.

In general, students felt that cheating on tests was more serious compared to homework, which is probably a rationalization to justify cheating on homework as a time management tool. Also, a majority of students identified looking at another student's test, passing answers during tests and copying another student's homework assignment as clearly cheating. But relatively large numbers of students admitted to having cheated in these ways, suggesting a disconnect between what students consider cheating and their behavior.

When asked how often they cheat, students reported cheating on $8.6 \%$ of homework assignments and roughly 1 test per year. But respondents felt that other students cheated on homework twice as often. In fact, $95 \%$ of students felt that their friends were more likely to cheat than they were.

When asked what the instructor could do to reduce cheating in the classroom, respondents overwhelmingly indicated (4.45 out of 5.00) that they would be less likely to cheat if the instructor wrote fair tests. Students also listed having an instructor that cared about their learning, being allowed to work in groups on homework and having openbook tests as factors that would tend to reduce their cheating. The following section will discuss specific approaches used by the author as a result of this information. This indicates that faculty can play a direct role in reducing the frequency of cheating in ways that many traditional faculty may not consider. Some of these techniques are discussed in the next section.

\section{Techniques for Minimizing Cheating}

\section{Write fair tests}

From the results of the survey, students felt that the most effective method of reducing cheating was for the faculty to write fair tests. Students were not asked specifically what "fair" meant. However, in informal discussions after the survey was administered, students indicated that this did not mean that tests could not be difficult. To the contrary, tests should be challenging and straightforward, but not overwhelming and convoluted. Furthermore, tests that are perceived as being based on pointless memorization are known to encourage cheating ${ }^{2}$. Students often complain about professors who write tests on material that was never covered in class or that are too long for the time given. This may be a particularly important observation considering that students view cheating on tests as a very serious discretion. Signs of cheating may be a strong indication that the instructor is not preparing suitable examinations.

To address this issue, the author has used learning objectives to help in constructing tests and assignments for the past two terms. Each topic in the course has a corresponding list of learning objectives. When constructing the test, the author 
selects several learning objectives deemed most important (the number varies with the length of the test) and writes the problems directly from these. All learning objectives are available to students on the course web page. In this way, students are aware of what is expected of them in the class up-front, rather than having to guess what the instructor might put on the exam. In addition, each exam includes one or two learning objectives from the upper levels of Bloom's Taxonomy ${ }^{6}$, which are usually written as short answer or essay questions. Such questions help to minimize student cheating because they require an original response. Since using learning objectives, there have been no complaints about unfair tests and no indications of student cheating on tests in the MFGE-370 course when taught by the instructor. At the end of the term, a small number of students were asked to complete a second survey, in which $100 \%$ indicated that they were less likely to cheat on tests in MFGE370 compared to other courses.

The length of a test is also an important consideration. If students know that they can expect to finish the exam in the time provided, they will be far less likely to cheat. A good tip for writing tests of a suitable length is to give students 3-4 times longer to take the test than the instructor would need. Stick to this rule. If you go over the time allotted, remove questions until you meet the maximum time. It is better to assess the knowledge of students thoroughly on fewer questions than to test how quickly they can partially answer many questions. The author prefers to use a factor of 4 in timing because short answer questions often take longer to complete given the writing involved.

Care about student learning

Students also reported that they would be less likely to cheat if they felt that the instructor cared more about their learning. The author has attempted to address this issue by discussing learning styles in class. At the beginning of the term, the author gives a short lecture on various models of learning and approaches that students can use to improve their learning. This is also an excellent opportunity to discuss cheating and to encourage honest behavior. Students are asked to take the Felder Learning Styles Indicator ${ }^{7}$ on-line and use the results for self-awareness of their own learning style. Students have responded favorably to this activity in informal discussions and have even reported using the suggestions in other courses beyond MFGE-370. The purpose of this activity is to develop an environment within the classroom where learning and honesty are valued. It is critical that these initial discussions be reinforced with recurring encouragement, modeling and valuing of learning and honest behavior. Therefore, it is crucial to talk with students whenever possible about their progress in the class in terms of learning. This can be done informally before and after class or during office hours, or formally on a mid-term course evaluation or during required student-instructor conferences.

\section{Organize Cooperative Learning Groups}

A complete discussion of the benefits of cooperative learning is beyond the scope of this paper. However, one benefit that seems to have been overlooked is its influence on student cheating. Many faculty view allowing students to work in groups as a 
recipe for student cheating. However, $100 \%$ of respondents to the author's survey reported working in groups on homework assignments. Since we are unlikely to control student behavior outside of class, and since there are significant ethical questions about even trying, faculty may as well use student homework groups to their advantage. The author assigns students in MFGE-370 to formal cooperative learning groups ${ }^{8}$ at the beginning of the term. These groups then work on bi-weekly homework assignments. Homework assignments are developed at the upper levels of Bloom's Taxonomy to avoid making the problems too trivial for a group to work on. Many of these problems are design-type problems, where the students are expected to define the problem, establish their assumptions and selection criteria, propose viable design options and select the most appropriate design. Completed assignments are then submitted in the form of technical reports or memos.

When properly used, cooperative learning creates a group dynamic where the individual's success is dependent on group collaboration. The result is that most groups will not allow members to copy each other's assignments for fear that they will not learn the material, which could have negative consequences for the grades of all group members. For example, formal cooperative learning groups in MFGE-370 that score an average grade of 85 or higher on a test receive a 3-5 point bonus to their score. In informal discussions with the instructor, students who said they normally cheated on homework were less likely to do so for fear of letting their group members down.

\section{Allow reference sheets on tests}

In MFGE-370 students are encouraged to bring a single sheet of 8 1/2 in. x 11 in. paper to a test with any information they would like on the paper. This accomplishes two goals. The first is to reduce the chance that students will cheat during a test since they would have the necessary information in front of them. Students felt that having a reference sheet would make cheating less likely. In addition, the act of putting a reference sheet together reinforces student learning by forcing students to work through their course notes and synthesize the most important information. Students can use the learning objectives to reduce the amount of information they must review and then determine what material should go onto their reference sheets. This helps them to use their study time more efficiently and requires them to re-write their notes - a good method for improving knowledge retention. The use of reference sheets also allows tests to be written with more emphasis on the upper levels of Bloom's Taxonomy (i.e. analysis, synthesis and evaluation).

Analysis of student exam scores before and after the above techniques were emphasized, as a secondary means of examining the effectiveness of these techniques, provided no evidence of a change in student performance. Composite exam grades for the Spring 2000 quarter, when the techniques described above were not emphasized, and Summer 2000, when a distinct effort was made to minimize cheating, are provided in Figure 1. Given this it would be difficult to draw any reasonable conclusions from exam data without considerable speculation. One could argue that scores should decrease when the

\footnotetext{
"Proceedings of the 2001 American Society for Engineering Education Annual Conference \& Exposition Copyright @ 2001, American Society for Engineering Education”
} 
above techniques are applied because the level of cheating would be reduced. On the other hand, grades could arguably increase as many of the above techniques are also thought to improve student learning and motivation.

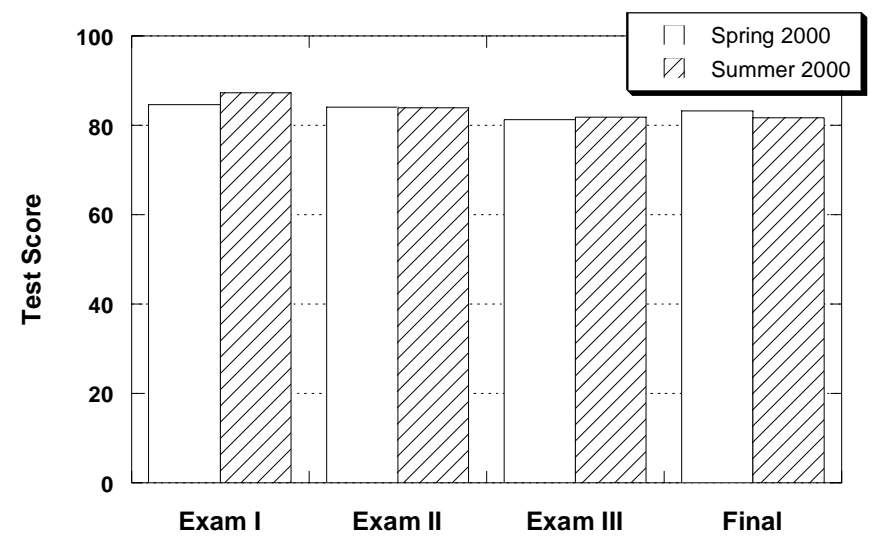

Figure 1 - Student scores on three exams and a cumulative final during the Spring 2000 and Summer 2000 quarters. During the Summer 2000 term techniques for reducing cheating were emphasized.

\section{Conclusions and Future Research}

Cheating is a problem common to almost all classes on nearly every campus across this country, and the problem is particularly serious among engineering students. But dealing with academic dishonesty is not a trivial matter. A successful approach likely includes institutional policies; open communication between students, administrators and faculty; and specific pedagogical approaches to reducing both student opportunities and pressures to cheat. This paper has outlined several potential methods that faculty can use within their own classes that may reduce the temptation to cheat for students.

In future research the author plans to expand the survey to look at academic dishonesty among engineering students in greater depth. The survey will be administered to students at Kettering University as well as a large, 4-year public university and to one or more community colleges to examine demographic influences on perceptions and frequency of cheating among students. Students will also be asked to reflect on their own moral feelings about cheating and the situational factors that might influence those beliefs and to comment on a wider range of faculty approaches to dealing with cheating. In a later phase of the research, focus groups will be formed that will seek to compare student and faculty perceptions of the severity of cheating on campuses. 


\section{References}

1 Maramark, S. and Maline, M.B., Issues in Education: Academic Dishonesty Among College Students, Washington D.C.: U.S. Department of Education, Office of Educational Research and Improvement, 1993.

2 Cizek, G.J., Cheating on Tests: How to Do It, Detect It, and Prevent It, Mahwah, NJ: Lawrence Erlbaum Associates, 1999.

3 Schneider, A., "Why professors don't do more to stop students who cheat," The Chronicle of Higher Education, Washington, 45(20), A8-A10, Jan. 22, 1999.

4 Meade, J., "Cheating: Is academic dishonesty par for the course?, Prism, 1(7), 30-32, 1992.

5 Schneider, A., "Why professors don't do more to stop students who cheat", The Chronicle of Higher Education, 45(20), A8-A10, Jan. 22, 1999.

6 Bloom, B.S., Taxonomy of Educational Objectives, Handbook I: Cognitive Domain, New York: Longmans, Green, 1956.

7 Richard Felder's "Index of Learning Styles" can be found at http://www2.ncsu.edu/effective_teaching/

8 Johnson, D.W., Johnson, R.T. and Smith, K.A., Active Learning: Cooperating in the College Classroom, $2^{\text {nd }}$ Ed., Edina, MN: Interaction Book Co., 1998.

\section{TREVOR HARDING}

Trevor Harding is an assistant professor of Manufacturing Engineering at Kettering University. He received his Ph.D. at the University of Michigan in Materials Science and Engineering, where he also received his BSE and MSE degrees. He has taught courses in materials engineering and materials in manufacturing processes. He is actively involved in the Teaching Fellows Program at Kettering University and the ERM Division of ASEE. His research interests include small crack fatigue crack growth in intermetallic alloys, viscoplasticity modeling in metal matrix composites and understanding the root causes of academic dishonesty. 